\title{
ROLE OF INCISION SITE IN REDUCING SURGICALLY INDUCED ASTIGMATISM IN MANUAL SMALL INCISION CATARACT SURGERY
}

K. Sathish, D. N. Prakash, Gunderao Shilpa, Kaup Soujanya,B. K. Kanchana, Ambika A. Acharya, Amar Kulkarni, Uma Balakrishnan.

1. Associate Professor. Department of Ophthalmology, Krishnarajendra Hospital, Mysore Medical College \& Research Institute, Mysore.

2. Assistant Professor. Department of Ophthalmology, Krishnarajendra Hospital, Mysore Medical College \& Research Institute, Mysore.

3. Resident. Department of Ophthalmology, Krishnarajendra Hospital, Mysore Medical College \& Research Institute, Mysore.

4. Resident. Department of Ophthalmology, Krishnarajendra Hospital, Mysore Medical College \& Research Institute, Mysore.

5. Resident. Department of Ophthalmology, Krishnarajendra Hospital, Mysore Medical College \& Research Institute, Mysore.

6. Resident. Department of Ophthalmology, Krishnarajendra Hospital, Mysore Medical College \& Research Institute, Mysore.

7. Resident. Department of Ophthalmology, Krishnarajendra Hospital, Mysore Medical College \& Research Institute, Mysore.

8. Resident. Department of Ophthalmology, Krishnarajendra Hospital, Mysore Medical College \& Research Institute, Mysore.

\section{CORRESPONDING AUTHOR:}

Dr. K. Sathish,

No. 826-I,'USHE',

$9^{\text {th }}$ B Cross Road, Roopa Nagar,

Mysore- 570026.

E-mail: drsathishkeshav@gmail.com

INTRODUCTION: Phacoemulsification and foldable IOLs allow modern day surgeon to aim at minimal induction of any astigmatic error as well as correct any pre-operative refractive errors thus making patients' life, spectacle free i.e. unaided emmetropia. But its high price and maintenance with a long learning curve for the surgeon make it unsuitable for the Indian camp scenario.

Manual SICS in comparison needs a larger incision for both nucleus removal and a rigid IOL insertion, but still provides for a sutureless and convenient alternative to phaco. Manual SICS does induce some amount of astigmatism by altering corneal curvatures (i.e., by coupling effect), while phaco surgery with $3 \mathrm{~mm}$ incision is astigmatically neutral. Manifold of studies have been done to compare Surgically Induced Astigmatism of manual SICS to phaco surgery but not much has been done to compare various techniques in manual SICS itself.

In this study an attempt has been made to analyze the role of incision site depending on the pre operative keratometry readings in reducing surgically induced astigmatism in manual small incision cataract surgery.

AIM: To assess the amount of surgically induced astigmatism by choosing scleral incisions based on pre operative keratometry reading.

MATERIALS AND METHODS: 


\section{INCLUSION CRITERIA}

Visually significant cataracts -

1. PSC,

2. NS grade II - III,

3. Mature cataract,

4. Hypermature cataract.

\section{EXCLUSION CRITERIA}

1. Nuclear cataract grade IV

2. Cataract with retinal pathology like macular lesions, diabetic and vascular retinopathy etc.

3. Cataract with Pseudoexfoliation syndrome.

4. Cataract with advanced glaucomatous cupping

5. Complicated cataract

6. Subluxated / Dislocated cataract

7. Paediatric cataract

8. Traumatic cataract

9. Cataract with Corneal opacity

10. Posterior polar cataract

11. Cataract with Rigid pupil

12. Cataract with corneal Astigmatism $>4 \mathrm{D}$

13. Cataract with Keratoconus

A study was conducted at KR Hospital, Mysore between April 2009 and March 2011. A retrospective analysis of 1000 cases meeting the inclusion and exclusion criteria were selected for this study. Initial screening was done by Optometrists and later examined by surgeons at the hospital on the same day. Detailed history, examinations and investigations were carried out by resident doctors like slit lamp biomicroscopy, tonometry, lacrimal sac syringing, fundus examination, keratometry and A-scan biometry. Pre operative emphasis was laid on keratometry and A-scan and was repeated on both eyes. Patients were posted for surgery on the next day and 2 experienced surgeons performed all the surgeries.

Site of incision was chosen according to pre-operative keratometric reading. Incision site was chosen along the steeper meridian (i.e., superior incision for WTR astigmatism and temporal incision for ATR astigmatism). Caliper controlled incisions were taken $-6 \mathrm{~mm}$ length, frown shaped, $2.5-3 \mathrm{~mm}$ posterior to limbus. Sclerocorneal tunnel with formation of corneal valve was made. Continuous curvilinear capsulorrhexis was attempted in all cases. Viscoelastics were used generously. Minimal iris handling was ensured. In-the-bag placement of IOL was done.

Patients were examined on the first post operative day, at first week and at the end of $6 w k s$. Post operative vision and refraction was performed at the end of 6 wks.

Surgically induced astigmatism was calculated using scalar analysis i.e. by subtracting the two K readings on that day from their respective ones preoperatively and adding the two differences. 
RESULTS:

- Age: Ranged from 50 to 80 years

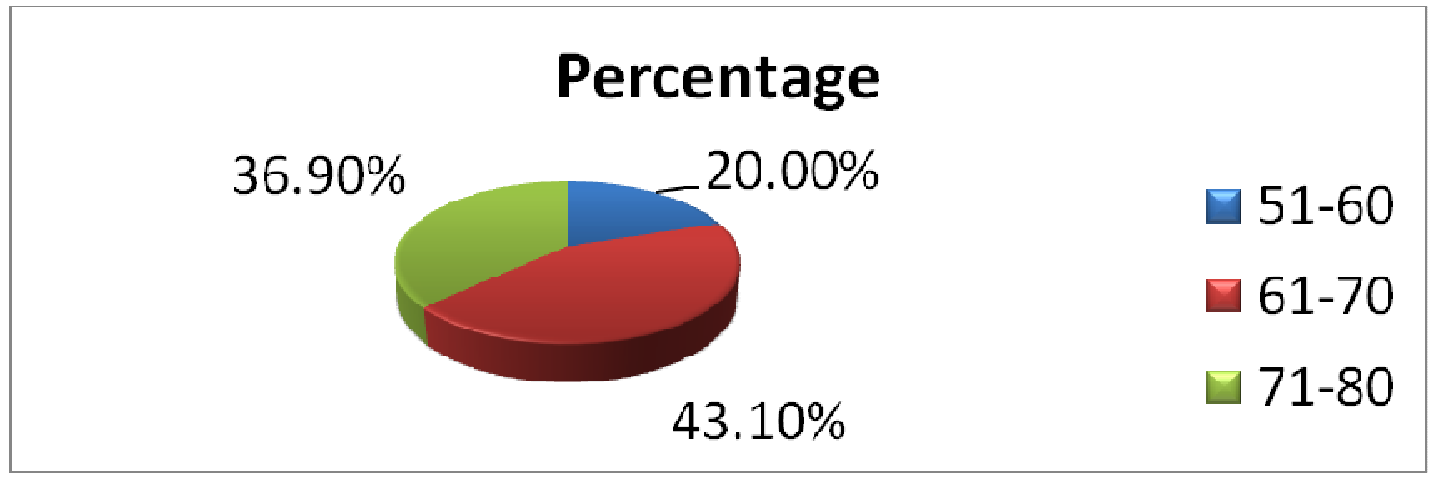

- $\operatorname{Sex}$

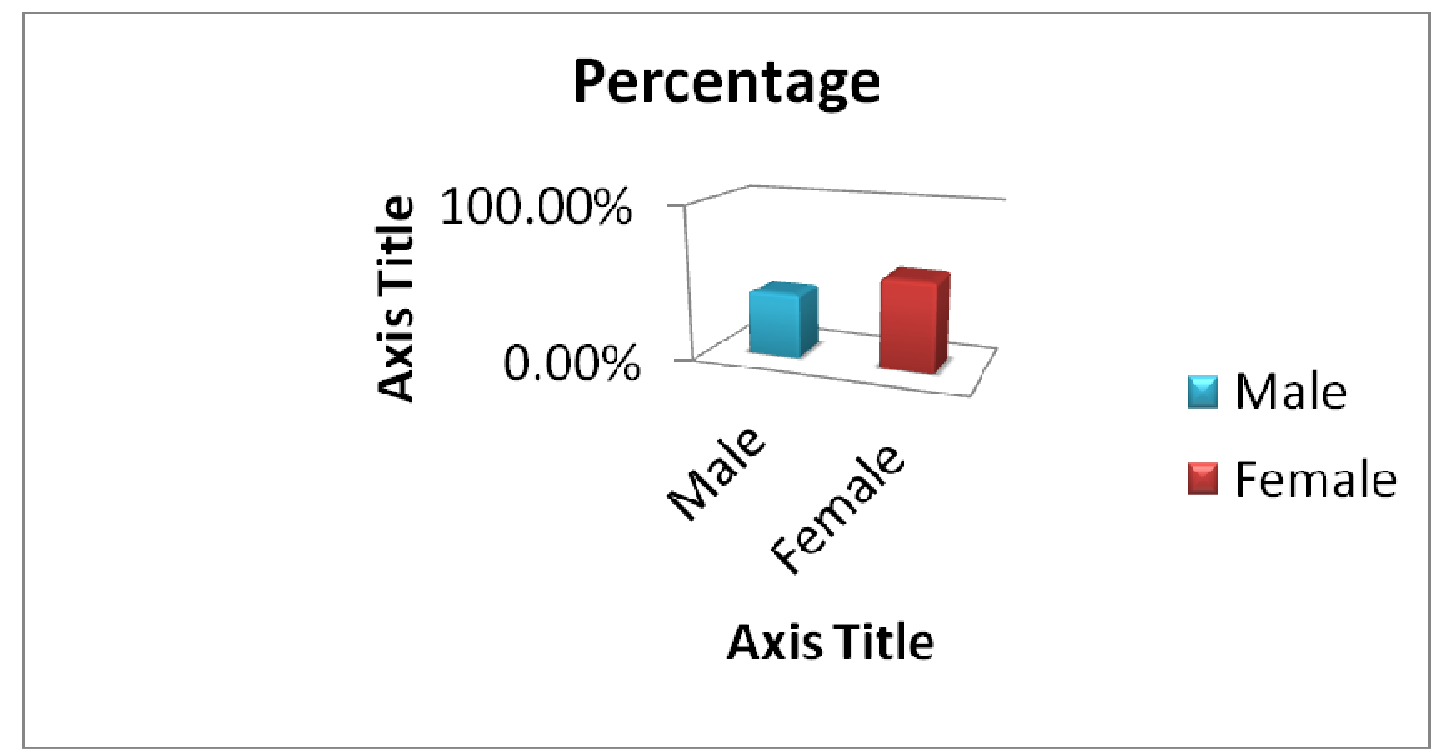

- Type of cataract

\begin{tabular}{|l|l|l|}
\hline Type of cataract & $\begin{array}{l}\text { Number } \\
\text { patients }\end{array}$ & Percentage \\
\hline $\begin{array}{l}\text { Posterior } \\
\text { Subcapsular } \\
\text { Cataract }\end{array}$ & $\mathbf{4 2 2}$ & $\mathbf{4 2 . 2 \%}$ \\
\hline $\begin{array}{l}\text { Nuclear Sclerosis } \\
\text { Grade I to III }\end{array}$ & 194 & $19.4 \%$ \\
\hline $\begin{array}{l}\text { Mature Cataract } \\
\text { Hypermature }\end{array}$ & 254 & $25.4 \%$ \\
\hline $\begin{array}{l}\text { Cataract } \\
\text { Test statistics }\end{array}$ & 130 & $13.0 \%$ \\
\hline
\end{tabular}




\section{Preoperative Astigmatism}

\begin{tabular}{|c|c|c|c|c|}
\hline \multirow{2}{*}{$\begin{array}{l}\text { Amount of } \\
\text { Astigmatism }\end{array}$} & \multirow{2}{*}{$\begin{array}{l}\text { Number of } \\
\text { Patients }\end{array}$} & \multirow{2}{*}{ Percentage } & \multicolumn{2}{|c|}{ Type } \\
\hline & & & ATR & WTR \\
\hline 0.0 to 0.25 & 128 & $12.8 \%$ & 87 & 41 \\
\hline 0.25 to 0.5 & 191 & $19.1 \%$ & 135 & 56 \\
\hline 0.5 to 1.0 & 281 & $28.1 \%$ & 205 & 76 \\
\hline 1.0 to 1.5 & 292 & $29.2 \%$ & 218 & 74 \\
\hline 1.5 to 2.0 & 108 & $10.8 \%$ & 87 & 21 \\
\hline Total & 1000 & & 732 & 268 \\
\hline $\begin{array}{l}\text { Test } \\
\text { statistics }\end{array}$ & Chi-squa & 43.77; P=.000 & & \\
\hline
\end{tabular}

- Uncorrected visual acuity at the end of 6 weeks

\section{Distant vision}

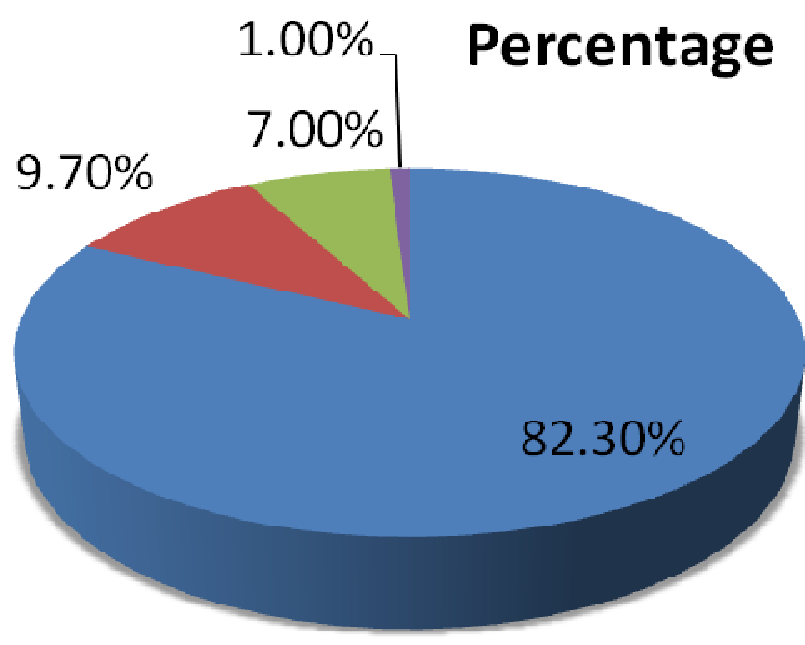

$6 / 9$ to $6 / 6$

- 6/12 to $6 / 9 p$

$6 / 18$ to $6 / 12 p$

$<6 / 18$

Near vision 


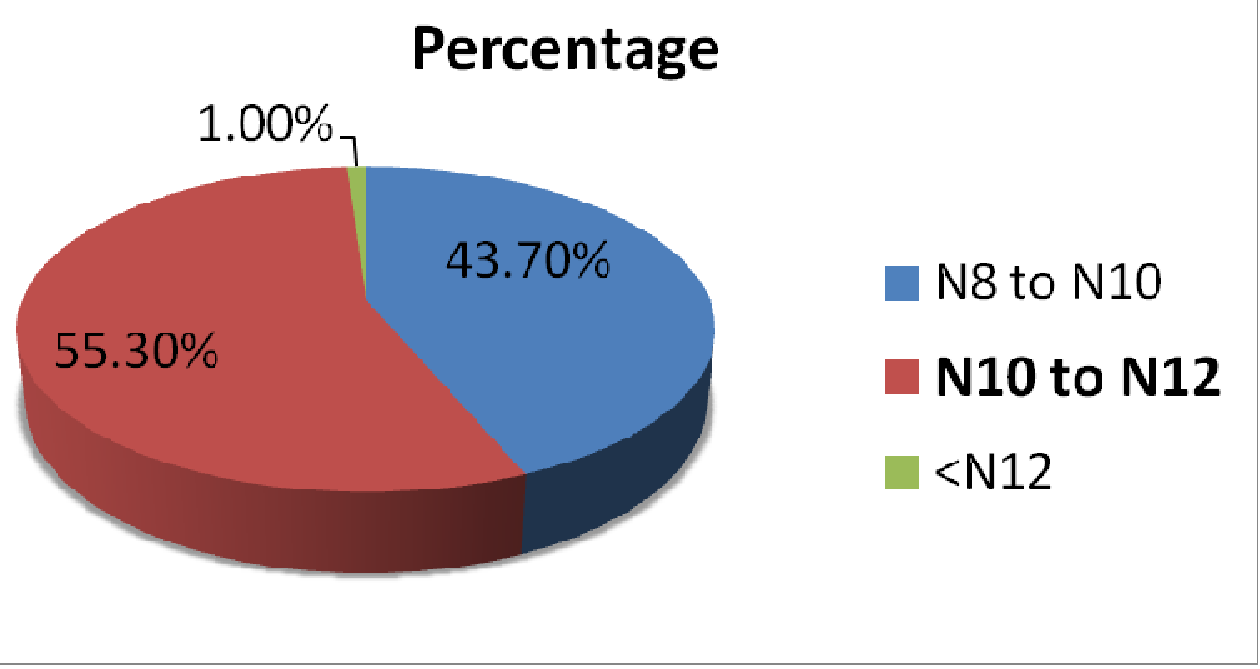

Best corrected visual acuity at the end of 6 weeks

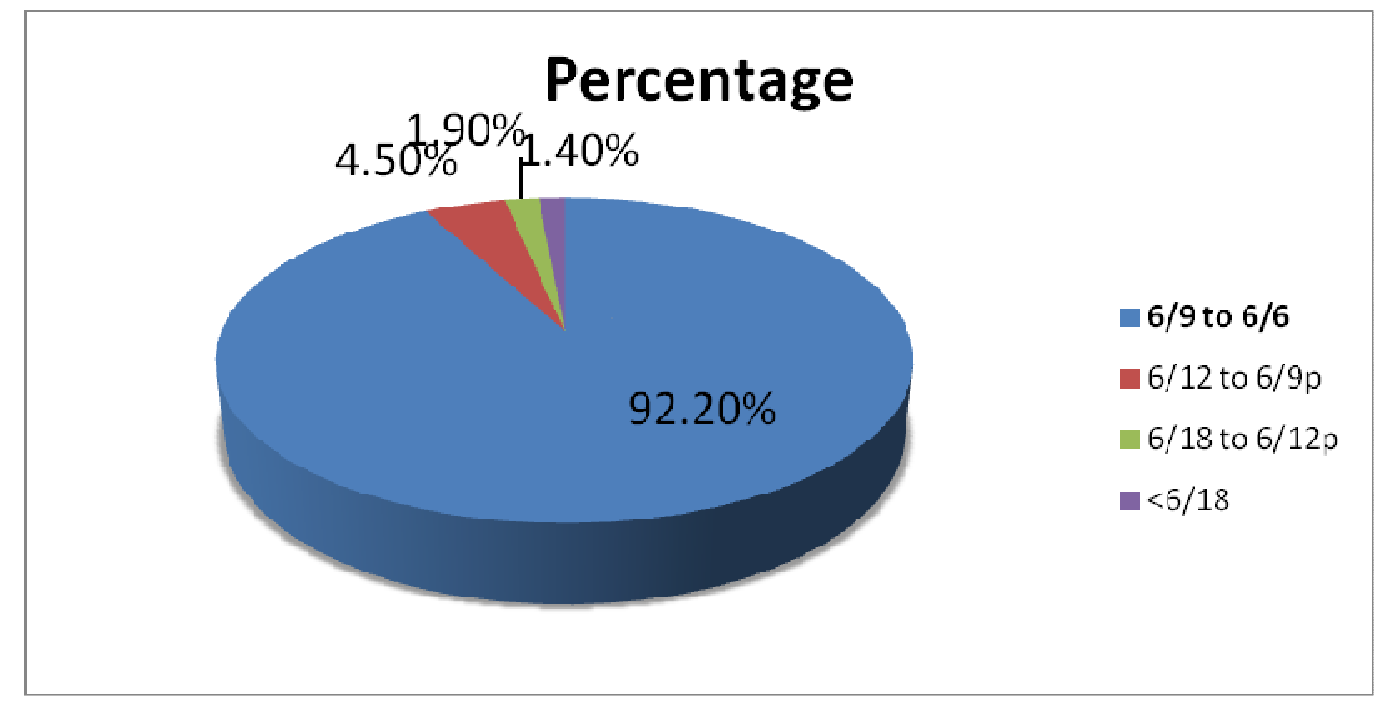

- Post operative surgically corrected astigmatism at the end of 6 weeks

\begin{tabular}{|l|l|l|l|l|}
\hline $\begin{array}{l}\text { Surgically } \\
\text { Induced } \\
\text { astigmatism }\end{array}$ & $\begin{array}{l}\text { Number } \\
\text { of } \\
\text { patients }\end{array}$ & Percentage & $\begin{array}{l}\text { With the } \\
\text { Rule }\end{array}$ & $\begin{array}{l}\text { Against } \\
\text { the Rule }\end{array}$ \\
\hline 0.0 to 0.5 & 45 & $4.5 \%$ & 18 & 27 \\
\hline 0.5 to 1.0 & 298 & $29.8 \%$ & 133 & 165 \\
\hline 1.0 to 1.5 & 628 & $62.8 \%$ & 318 & 310 \\
\hline$>1.5$ to 2 & 29 & $2.9 \%$ & 10 & 19 \\
\hline Test statistics & Chi-square=944.22; P=.000 \\
\hline
\end{tabular}




\section{DISCUSSION:}

- Today's cataract incisions provide better control of surgically induced astigmatism, either by using temporal approach to produce astigmatically neutral surgery or by using on axis incision to induce astigmatism at the steep axis to counteract preexisting astigmatism.

- In the present study, the astigmatism which can be corrected by placing the incision according to the preoperative keratometric values shows that postoperative astigmatism can be minimized or to some extent can be corrected by planning the correct placement of incision.

- Our study showed that superior incision induced a mean SIA of about 1.3D ATR and temporal incision induced a mean SIA of about 1D which is comparable with other studies done by Tejedol \& Murube where superiorly placed incision induced SIA if about 1.5D. In another study done by Haldipurkar et al showed that superiorly placed incision induced ATR of about 1.2D. In study done by Kimura et al showed that superiorly place incision induced SIA of about $1.41 \pm 0.72$ and temporally placed incision induced SIA of about $1.02 \pm 0.66$. Our results were also comparable to a similar study done by Nikhil S. Gokhale and Saurabh Sawhey in the year 2005.

- Hence superiorly placed incision helps to neutralize a pre-existing WTR astigmatism up to $2 \mathrm{D}$ and to reduce significant WTR astigmatism of $>2 \mathrm{D}$ and temporally placed incision helps to neutralize smaller degrees of pre-existing ATR astigmatism. Thus the net effect is reduction of pre-existing astigmatism rendering the patients nearly emmetropic.

CONCLUSION: It is possible to reduce the amount of post operative astigmatism significantly by choosing the incision site depending on the pre operative $\mathrm{K}$ readings thus rendering the patient nearly emmetropic.

\section{BIBILIOGRAPHY:}

1. Albert, Jakobiec. Principles and Practice of Ophthalmology. 2nd ed. Philadelphia: WB Saunders; 2:2000.

2. Daviel Jacques. Cited in Duke Elder's System of Ophthalmology. 1748;11:253..

3. Girard LJ, Hoffman RF. Scleral tunnel to prevent induced astigmatism. Am J Ophth 1984;97:450-6.

4. $\quad$ Shepherd JR. Induced astigmatism in SICS. J Cat \& Ref Surg 1989;15:85-8.

5. Singer JA. Frown incision for minimising induced astigmatism after SICS with rigid IOL implantation. J Cat \& Ref Surg 1991;17:677.

6. Jaffe NS, Jaffe MS, Jaffe GF. Cataract surgery and its complications. 5th ed. CV Mosby; 1990. pp. 132-46.

7. Gogate PM, Kulkarni SR, Krishnaiah S, Deshpande RD, Joshi SA, Palimkar A, Deshpande MD. Safety and efficacy of phacoemulsification compared with manual small-incision cataract surgery by a randomized controlled clinical trial: six-week results. Ophthalmology. 2005 May;112(5):869-74.

8. A Hennig, J Kumar, D Yorston, A Foster. Sutureless cataract surgery with nucleus extraction: outcome of a prospective study in Nepal. BrJ Ophthalmol 2003;87:266-270

9. Alpins NA, Goggin M,Practical Astigmatism Analysis for Refractive Outcomes in Cataract and Refractive Surgery, Surg ophthalmol 2004;49(1):109-122 
10. Albert, Jakobiec. Principles and Practice of Ophthalmology. 2nd ed. Philadelphia: WB Saunders 2000;2:1540.

11. Gokhale Nikhil S, Sawhney Saurabh. Reduction in astigmatism in manual SICS changing site of incision. Indian J Ophth 2005;53(3):201-3.

12. Morlet N, Minassian D, Dart J. Astigmatism and the analysis of its surgical correction. Br J Ophthalmol 2001;85:1127-1138

13. Holladay JT, Dudeja DR, Koch DD. Evaluating and reporting astigmatism for individual and aggregate data . J Cataract Refract Surgery 1998;24:57-65.

14. Kronish JW, Forster RK. Control of Corneal Astigmatism Following Cataract Extraction by Selective Suture Cutting. Arch Ophthalmol. 1987;105(12):1650-1655.

15. John M, Lei Zheng, Joanna M, Marcoz, Bo Lindstrom. The effect of incisions for cataract on corneal curvature. Ophthalmology 2003;110(9):1807-13.

16. Naeser K, Behrens JK, Naeser EV. Quantitative assessment of corneal astigmatic surgery: expanding the polar values concept. J Cat \& Ref Surg 1994;20:162-8.

17. Spaeth GL. Ophthalmic Surgery: Principles and Practice. Scleral Tunnel Incisions 3rd ed. pp. 51-6. 